Research Paper:

\title{
The Reliability and Validity of the Persian Version of Pittsburgh Sleep Quality Index in Iranian People
}

\author{
Naser Mohammad Gholi Mezerji ${ }^{1}$ (D), Parisa Naseri² ${ }^{2}$, Zohreh Omraninezhad ${ }^{3}$, Zahra Shayan ${ }^{4^{*}}$ (iD)
}

1. Department of Biostatistics and Epidemiology, School of Health, Students Research Committee, Hamadan University of Medical Sciences, Hamadan, Iran 2. Department of Biostatistics, School of Allied Medical Sciences, Shahid Beheshti University of Medical Sciences, Tehran, Iran. 3. Department of Biostatistics, School of Health, Arak University of Medical Sciences, Arak, Iran.

4. Trauma Research Center, Department of Biostatistics, School of Medicine, Shiraz University of Medical Sciences, Shiraz, Iran.

\begin{tabular}{l|l}
$\begin{array}{l}\text { Use vourdevice to san } \\
\text { and read the article online }\end{array}$ & $\begin{array}{l}\text { Cftation Mohammad Gholi Mezerji N, Naseri P, Omraninezhad Z, Shayan Z. The Reliability and Validity of the Persian Ver- } \\
\text { sion of Pittsburgh Sleep Quality Index in Iranian People. Avicenna J of Neuropsychophysiology. 2017; 4(3):95-102. http://dx.doi. } \\
\text { org/10.32598/ajnpp.4.3.95 }\end{array}$ \\
dol'http://dx.doi.org/10.32598/ajnpp.4.3.95
\end{tabular}

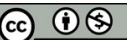

Article info:

Received: 10 Dec 2016

Accepted: 15 Apr 2017

Available Online: 01 Aug 2017

Keywords:

Sleep, Psychometrics, Reliability and validity, Factor analysis

\section{ABSTRACT}

Introduction: Sleep disturbances are a significant public health issue and such problems are associated with a number of psychiatric disorders. The Pittsburgh Sleep Quality Index (PSOI) is an effective instrument frequently used to evaluate sleep style and quality.

Objectives: The present study aimed to assess the reliability, validity, and factor structure of the Persian version of PSQI.

Materials and Methods: This cross-sectional study was conducted on 1115 citizens of Arak City, Iran aged $18-60$ years. They were selected by stratified random sampling method from different parts of the city. The following aspects of the Persian version of PSQI were evaluated to assess its validity and reliability. To assess the validity of the content, the questionnaire was sent to a panel of 15 academic members consisting of experts in the fields of psychology and health education. The internal consistency of the PSQI questionnaire was evaluated by the Cronbach alpha coefficient and item-scale correlation. To investigate the factor structure of the PSOI, Exploratory Factor Analysis (EFA) was performed with a 2-factor solution and varimax rotation. The extraction of principal factors was performed after varimax orthogonal rotation and Kaiser's criterion. At last, Confirmatory Factor Analysis (CFA) was applied to assess the reliability of the PSQI questionnaire. All analyses were performed in SPSS V. 16.0 and AMOS for Windows.

Results: The Persian version of PSQI was evaluated in the study with regard to its internal consistency and factor structure. The result showed excellent item content validity index $(\geq 0.78)$ and excellent scale content validity index $(\geq 0.90)$. The result of the Cronbach alpha coefficient was 0.65 . The factors of perceived sleep quality and sleep efficiency were extracted by means of factor analysis and these two factors explained $51.75 \%$ of the total variance. Confirmatory factor analysis results show the model's satisfactory fitting based on adequacy criteria goodness of fit index, goodness of fit index adjusted for degrees of freedom, root mean square error of approximation, and comparative fit index. The nonnormed fit index was close to its reference value of 0.90 .

Conclusion: In general, findings suggest that the Persian version of PSQI displayed satisfactory validity and reliability to measure the quality of sleep of Iranian people, at least citizens of Arak City, Iran. 


\section{Introduction}

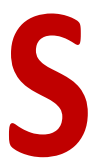

leep is a physical and mental resting state in which a person becomes relatively inactive and careless of their environment. Sleep problems include the inability to fall asleep or go back to sleep and frequent waking up during the night; such problems affect not only occupational and educational functioning but also the safety and quality of life. Sleep disorders can increase tension; cause irritability, depression, and confusion; and have an adverse impact on the quality of life in general [1].

Different instruments such as several questionnaires have been developed to assess sleep disturbances. Standardized questionnaires provide comprehensive assessments of sleep quality, but these questionnaires are few. One of the most widely used instruments in clinical and research settings is the Pittsburgh Sleep Quality Index (PSQI) questionnaire. This questionnaire was introduced by Buysse as a fast and valid instrument for determining sleep quality and sleep disorders [2]. Different studies applied PSQI for detecting sleep disorders among the general population [3], working people [4], and clinical populations [5-9]. The PSQI has been evaluated for its reliability and validity in different populations as different cultures have different perceptions of sleep and its problems. Cole examined the factor structure of the PSQI using confirmatory factor analysis in older adults. The study found that a 3-factor model was a better fit than a 1-factor model [10].

A study done by Aloba, however, confirmed a 3-factor model generated by principal component analysis with the best cut-off score at 5 (sensitivity 0.720 , specificity 0.545 , and overall correct classification rate of 0.554 ) among Nigerian university students. The concurrent validity of the PSQI is further supported by its modest correlation with the General Health Quality (GHQ)-12 scores $(r=0.252, P<0.001)$ [11]. Burkhalter conducted a confirmatory factor analysis of the PSQI in renal transplant recipients and concluded that the 3-factor model had a weak fit $\left[\chi^{2}=11.850, \mathrm{df}=8, \mathrm{P}=0.408\right.$; Root Mean Square Error of Approximation (RMSEA) $=0.060$; Weighted Root Mean square Residual (WRMR)=0.384; Confirmatory Fit Index (CFI)=0.992] [12].

Mariman used factor analysis for validation of the PSQI in patients diagnosed with chronic fatigue syndrome and obtained a 3-factor model. All factor loadings were significant and all goodness-of-fit values were in acceptable range $\left[\chi^{2}=14.70, d f=11, P=0.20\right.$; Goodness of Fit In$\operatorname{dex}(\mathrm{GFI})=0.99$; Adjusted Goodness of Fit Index (AGFI) for Degrees of Freedom=0.97; $\mathrm{CFI}=0.99$; RMSEA=0.03; The Consistent version of the Akaike Information Criterion $(C A I C)=134.10]$. Similarly, the 1-factor model suggested by Buysse et al. indicated a poor fit with the data $\left(X^{2}=109.90, \mathrm{df}=14, \mathrm{P}<0.001 ; \mathrm{GFI}=0.92 ; \mathrm{AGFI}=0.85\right.$; $\mathrm{CFI}=0.84$; RMSEA=0.13; CAIC=208.23) [13]. Results of the study conducted by Tomfohr showed that a 3-factor model was better than 1-factor model in English speaking non-Hispanic whites and English and Spanish speaking Hispanics of Mexican descendens.

The Cronbach alpha values were stating of adequate internal consistency (Non-Hispanic Whites (NHW) $\alpha=0.775$; English-speaking Hispanics of Mexican Descent (HMD) $\alpha=0.741$; HMD $\alpha=0.770$ ) [14]. But in another study, Otte indicated a 2-factor model as the best model for breast cancer patients $\left(\chi^{2}=89.70, d f=13, P<0.05\right.$, Standardized Root Mean Square Residual (SRMR) $=0.0048$, Root-Mean Square Error Approximation (RMSEA) $=0.075, \mathrm{CFI}=0.98$ ) [15]. Cultural and demographic differences can lead to differences in factor structure results of the PSQI because sleep quality and perceptions of sleep are related to various factors such as sex, age, health, and culture. Therefore, this study aimed to assess the internal consistency, reliability, and factor structure of the PSQI for the citizens of Arak City, Iran.

\section{Materials and Methods}

\section{Study subjects}

A pilot study on 50 individuals was conducted to determine the internal consistency and item-total correlations of the PSQI. This pilot study confirmed the reliability of the PSQI questionnaire. Then in a cross-sectional study, 1115 Arak citizens aged 18-60 years, were selected by stratified random sampling method in 2015 . In the first stage, the city was divided into three areas (S1, S2, and S3).

In the second stage, the samples were selected randomly from each area with proportional to area size (N1, N2, and N3). All participants provided verbal informed consent for using their information in this study. The participants were included in the study who were $\geq 18$ years old, with illiterate level education, without psychotic or cognitive disorders, and not hospitalized or received outpatient treatment in the last month. All samples were interviewed face to face by a trained researcher.

They completed the Persian version of the PSQI questionnaire. Their demographic and other comparative 
variables were assessed, too. The variables that may affect sleep were evaluated, such as age, sex, and education level. This study was approved by the Ethics Committee of Arak University of Medical Sciences and each sample expressed his or her consent for participation in the study.

\section{Study assessment}

The PSQI questionnaire was used to survey the sleep quality of the previous month of the participants. The PSQI is a 19-item self-report questionnaire. These 19 items assess seven components: Sleep quality, sleep latency, sleep duration, habitual sleep efficiency, sleep disturbance, use of sleeping medication, and daytime dysfunction. Each component is rated on a 0-3 scale, where 0 and 3 indicate no difficulty and severe difficulty, respectively. The scores of seven component are then summed up to yield a total score which has a range of 0-21; higher scores indicate worse sleep quality [2]

\section{Statistical analysis}

The PSQI questionnaire has a normal distribution. Thus, the results from parametric tests were proper for the PSQI. The descriptive statistics were computed for the total sample and separately for the male and female participants and stratified by age and education levels. For the PSQI, we presented the results as the Mean \pm SD or No. (\%).

For The Pittsburgh Sleep Quality Index (PSQI), the descriptive statistics were calculated for total and subscale scores. A PSQI total score $>5$ was used to define clinically significant abnormalities, as has been done in studies on young and middle-aged adults [2]. Pairwise comparisons were conducted with respect to the age groups (19-30, 31-50, and >51 years), educational level (under high school, high school, some college, college and graduate degree), and sex (male and female). The Independent samples t-test was used for quantitative sleep variables (PSQI total scores) and the Chi-square test was used for qualitative sleep variables (PSQI total score $>5$ vs. $\leq 5$ ).

\section{Validity}

To assess the validity of the test content, the questionnaire was sent to a panel of 9 academic members consisting of experts in the fields of psychology and health education. For each item, the Item Content Validity Index (I-CVI) was calculated as the number of experts giving a rating of either 3 or 4 , divided by the number of experts. For the Scale Content Validity Index (S-CVI), the calculated I-CVI for each item and then the average I-CVI were calculated across all items.

As Polit and Beck noted, for a scale to have excellent content validity, it should have items with I-CVIs of 0.78 or higher and S-CVI/Ave of 0.90 or higher [16]. The internal consistency of the PSQI questionnaire was evaluated by the Cronbach alpha coefficient and itemscale correlation.

\section{Reliability}

To investigate the factor structure of the PSQI, the Exploratory Factor Analysis (EFA) was performed with a 2-factor solution and varimax rotation. Kaiser-MayerOlkin (KMO) value and Bartlett's sphericity were reported, too. The correlations between each item and the total score of the specified factor were also calculated.

For the factorial analysis, the Kaiser-Meyer-Olkin (KMO) index and Bartlett-Test of Sphericity (BTS) were used as measures of adequacy of the sample size. Factor analysis is done to test the null hypothesis of the identity matrix, to verify no cross-correlation among variables and that all off-diagonal correlations are zero. KMO values $>0.50$ and $\mathrm{P}$ values $<0.05$ in Bartlett's test are considered adequate for the factorial analysis [17]. Principal components analysis was used to extract maximum variance (total variance explained for each factor) for decreasing a large number of variables into a smaller number of components [18].

\section{Confirmatory factor analysis}

To test the model's goodness of fit, we used model fit indexes, including the Chi-square test $\left(\chi^{2}\right)$ with significance greater than 0.05 , Chi-square ratio $\left(\chi^{2} / d f\right)$ with acceptable values below 2.0, Goodness of Fit Index (GFI) with acceptable values equal to or greater than 0.85 , GFI Adjusted Goodness of Fit Index (AGFI) with acceptable values equal to or greater than 0.80 , Root Mean square Residual (RMR) with acceptable values equal to or lower than 0.10, Root Mean Square Error of Approximation (RMSEA) with acceptable values equal to or lower than 0.08, Bentler Comparative Fit Index (CFI) with acceptable values equal to or greater than 0.90 , and finally Bentler and Bonett Non-Normed Fit Index (NNFI) with acceptable values equal to or greater than 0.90 .

At least three adequacy indexes with values greater than their references were considered in analyzing the goodness of fit of data to the proposed factors [19]. To 
estimate factor loads, we used the maximum likelihood method with a minimum of ten observations per item that represented univariate normality of items [20]. All analyses were done in SPSS version 16.0 (SPSS Institute, Chicago, Illinois) and AMOS for Windows. The significance level was set at 0.05 .

\section{Results}

Of 1115 participants who completed the PSQI questionnaires, 601 (54\%) were females and 511 (46\%) were males. Mean $\pm S D$ age of the participants was $29.93 \pm 10.22$ years (range: $18-60$ y). Also, almost half $(48 \%)$ of the participants passed a graduate degree. The demographic characteristics of participants are presented in Table 1.

\section{Descriptive statistics for PSQI}

Table 2 presents the frequency distributions of the total scores and subscales of the PSQI by age, education, and sex. The Mean \pm SD PSQI total score was 7.01 \pm 3.63 , and $72.40 \%$ of the total sample had a PSQI total score $>5$, indicating a significant abnormality in sleep quality. The participants with less education level reported worse sleep quality and usually obtained a PSQI total score $>5$. There was a significant difference between sex and PSQI total score $(P<0.001)$ or $P S Q I>5(P<0.001)$, indicating that women had worse sleep quality and usually obtained a PSQI total score $>5$. Age was not significantly associated with PSQI total scores or PSQI total score >5 (Table 2).

\section{Validity}

The validity of the Persian version of PSQI was evaluated by its internal consistency and factor structure. The result showed excellent I-CVI $(\geq 0.78)$ and S-CVI $(\geq 0.90)$ values. The Cronbach alpha coefficient was 0.65 . In order to examine the validity of the PSQI, the exploratory factor analysis was determined by application of varimax rotation and 2-factor solution. The result of KMO was 0.746 , and the Bartlett's sphericity was evaluated as significant at 0.05 . These two tests showed efficiency for the factor analysis in terms of structure detection on our dataset.

Two factors were extracted by factor analysis that explained $51.75 \%$ of the variance. Table 3 presents the factor loadings of each of the seven PSQI components on these two identified factors. The first factor consists of sleep quality, sleep disturbances, sleep latency, daytime dysfunction and use of sleep medication; the Cronbach alpha was obtained as 0.65 . The second factor consists of habitual sleep efficiency and sleep duration and the obtained Cronbach alpha was 0.57 . The correlation coefficient between the first factor and the second factor was $0.31(P<0.001)$.

\section{Reliability}

The reliability coefficient (the Cronbach alpha) of the PSQI questionnaire was determined as 0.65 . The Pearson correlations between component scores and the PSQI total score are presented in Table 4. The calculations showed the largest correlation coefficient for habitual sleep efficiency $(r=0.90, P<0.001)$, and the smallest correlation coefficient for the use of sleeping medication $(r=0.55, P<0.001)$.

\section{Confirmatory factor analysis}

Figure 1 displays the path diagram, illustrating the factor loads of the observed variables in the latent variables (sleep quality, sleep latency, sleep duration, habit-

Table 1. The demographic characteristics of the study participants ( $n=1115$ )

\begin{tabular}{|c|c|c|c|c|c|}
\hline \multicolumn{3}{|c|}{ Categories } & \multirow[t]{2}{*}{ Mean $\pm S D$} & \multirow{2}{*}{$\begin{array}{c}\mathbf{n} \\
514\end{array}$} & \multirow{2}{*}{$\begin{array}{c}\% \\
46.1\end{array}$} \\
\hline \multirow{3}{*}{ Age, y } & \multirow{3}{*}{ Sex } & Male & & & \\
\hline & & & \multirow[t]{2}{*}{$29.93 \pm 10.22$} & & \\
\hline & & Female & & 601 & 53.9 \\
\hline \multirow{5}{*}{ Education level } & & Illiterate & & 13 & 1.2 \\
\hline & & Primary & & 107 & 9.6 \\
\hline & & High school & & 101 & 9.1 \\
\hline & & College & & 359 & 32.2 \\
\hline & & Graduate degree & & 535 & 48 \\
\hline
\end{tabular}


Table 2. The descriptive statistics Mean $\pm \mathrm{SD}$, or \% for PSQI scores across demographic variables

\begin{tabular}{|c|c|c|c|c|c|c|c|c|c|c|}
\hline \multicolumn{2}{|c|}{ Categories } & \multirow{2}{*}{$\begin{array}{c}\text { PSQI } \\
\text { Total Score } \\
7.01 \pm 3.63\end{array}$} & \multirow{2}{*}{$\begin{array}{c}\begin{array}{c}\text { Habitual } \\
\text { Sleep } \\
\text { Efficiency }\end{array} \\
1.38 \pm 1.37\end{array}$} & \multirow{2}{*}{$\begin{array}{c}\begin{array}{c}\text { Sleep } \\
\text { Latency }\end{array} \\
1.41 \pm 0.97\end{array}$} & \multirow{2}{*}{$\begin{array}{c}\begin{array}{c}\text { Sleep } \\
\text { Duration }\end{array} \\
0.8 \pm 0.98\end{array}$} & \multirow{2}{*}{$\begin{array}{c}\begin{array}{c}\text { Sleep } \\
\text { Distur- } \\
\text { bances }\end{array} \\
1.2 \pm 0.57\end{array}$} & \multirow{2}{*}{$\begin{array}{c}\begin{array}{c}\text { Sleep } \\
\text { Quality }\end{array} \\
1.05 \pm 0.74\end{array}$} & \multirow{2}{*}{$\begin{array}{c}\begin{array}{c}\text { Use of } \\
\text { Sleeping } \\
\text { Medication }\end{array} \\
0.31 \pm 0.76\end{array}$} & \multirow{2}{*}{ 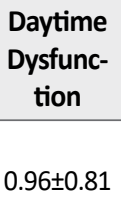 } & \multirow{2}{*}{$\begin{array}{c}\begin{array}{c}\text { Global } \\
\text { Score }>5 \\
\%\end{array} \\
\\
72.40\end{array}$} \\
\hline 華 & $\begin{array}{c}\text { Score } \\
(n=1115)\end{array}$ & & & & & & & & & \\
\hline \multirow{3}{*}{ 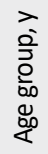 } & $18-30$ & $6.99 \pm 3.55$ & $1.47 \pm 1.38$ & $1.42 \pm 0.95$ & $0.72 \pm 0.93$ & $1.18 \pm 0.55$ & $1.05 \pm 0.75$ & $0.27 \pm 0.69$ & $0.99 \pm 0.81$ & 72.70 \\
\hline & $31-50$ & $6.91 \pm 3.7$ & $1.17 \pm 1.32$ & $1.37 \pm 0.99$ & $0.91 \pm 1.02$ & $1.3 \pm 0.57$ & $1.04 \pm 0.71$ & $0.34 \pm 0.83$ & $0.89 \pm 0.79$ & 71.10 \\
\hline & $>51$ & $7.82 \pm 4.03$ & $1.49 \pm 1.34$ & $1.48 \pm 1.12$ & $1.21 \pm 1.11$ & $1.46 \pm 0.6$ & $1.01 \pm 0.75$ & $0.5 \pm 1.04$ & $1.01 \pm 0.88$ & 75 \\
\hline \multirow{5}{*}{ 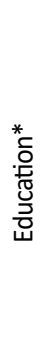 } & Illiterate & $10.30 \pm 3.22$ & $2.15 \pm 1.06$ & $2 \pm 0.91$ & $1.53 \pm 1.26$ & $1.69 \pm 0.48$ & $1.69 \pm 0.85$ & $0.3 \pm 0.85$ & $0.92 \pm 0.75$ & 99 \\
\hline & $\begin{array}{l}\text { Primary } \\
\text { school }\end{array}$ & $6.94 \pm 3.78$ & $1.22 \pm 1.36$ & $1.3 \pm 0.94$ & $0.81 \pm 1.02$ & $1.39 \pm 0.61$ & $1.02 \pm 0.78$ & $0.37 \pm 0.83$ & $0.93 \pm 0.88$ & 69.20 \\
\hline & $\begin{array}{l}\text { High } \\
\text { school }\end{array}$ & $7.01 \pm 3.53$ & $1.37 \pm 1.38$ & $1.4 \pm 1.02$ & $0.74 \pm 0.94$ & $1.21 \pm 0.59$ & $1 \pm 0.7$ & $0.34 \pm 0.78$ & $0.9 \pm 0.79$ & 74.40 \\
\hline & College & $6.98 \pm 3.49$ & $1.45 \pm 1.36$ & $1.4 \pm 0.96$ & $0.76 \pm 0.98$ & $1.26 \pm 0.56$ & $1.04 \pm 0.68$ & $0.34 \pm 0.81$ & $0.95 \pm 0.77$ & 74.30 \\
\hline & $\begin{array}{c}\text { Graduate } \\
\text { degree }\end{array}$ & $6.89 \pm 3.67$ & $1.35 \pm 1.38$ & $1.3 \pm 0.97$ & $0.81 \pm 0.96$ & $1.16 \pm 0.55$ & $1.05 \pm 0.77$ & $0.26 \pm 0.69$ & $0.99 \pm 0.82$ & 70.70 \\
\hline \multirow{2}{*}{$\stackrel{*}{*} \stackrel{*}{凶}$} & Female & $7.73 \pm 3.84$ & $1.54 \pm 1.35$ & $1.61 \pm 0.98$ & $0.92 \pm 1.04$ & $1.31 \pm 0.59$ & $1.09 \pm 0.75$ & $0.34 \pm 0.82$ & $1.05 \pm 0.85$ & 77.20 \\
\hline & Male & $6.17 \pm 3.15$ & $1.19 \pm 1.37$ & $1.17 \pm 0.91$ & $0.65 \pm 0.88$ & $1.14 \pm 0.52$ & $1 \pm 0.73$ & $0.25 \pm 0.67$ & $0.87 \pm 0.74$ & 66.70 \\
\hline
\end{tabular}

PSQI: Pittsburgh Sleep Quality Index; Higher scores indicate worse sleep quality (total PSQI scores range from 0-21). $\quad$ AJNPP

No significant differences between age categories $(\mathrm{P}=0.39)$ for $\mathrm{PSQ}$ l total score or for age categories $(\mathrm{P}=0.17)$ for $\mathrm{PSQ}>5$.

* Significant differences between education categories for PSQI total score $(\mathrm{P}=0.021)$ or PSQI $>5(\mathrm{P}=0.01)$; ** Significant differences between sex for PSQI total score $(\mathrm{P}<0.001)$ or $\mathrm{PSQI}>5(\mathrm{P}<0.001)$.

ual sleep efficiency, sleep disturbance, use of sleeping medication and daytime dysfunction), as well as the factors loading, factors covariance, and items variances.

Overall, factor loadings showed good values, when they are larger than 0.40 in their factors. The symbol demonstrated by the mark " $\mathrm{e}$ " is named error. The overall fitting results were $\chi^{2}=27.906 ; \chi^{2} / d f=2.326, P<0.006$; $\mathrm{GFI}=0.993 ; \mathrm{AGFI}=0.984 ; \mathrm{RMR}=0.020 ; \mathrm{RMSEA}=0.034$;
$\mathrm{CFI}=0.985$; and NNFI=0.974. These results show the model's satisfactory fitting based on adequacy criteria of GFI, AGFI, RMR, RMSEA, CFI, and NNFI. However $\chi^{2} / d f$ was close to its acceptable values below 2.0.

\section{Discussion}

This study aimed to determine factor structure and internal consistency of the Pittsburgh Sleep Quality Index (PSQI)

Table 3. Seven-factor loadings of PSQI obtained from varimax rotation

\begin{tabular}{ccc}
\hline Factor & Components & Factor Loadings \\
\hline & Sleep disturbances & 0.760 \\
Perceived Sleep Quality & Sleep quality & 0.659 \\
& Daytime dysfunction & 0.617 \\
& Use of sleeping medication & 0.614 \\
Sleep Efficiency & Sleep latency & 0.550 \\
& Habitual sleep efficiency & 0.816 \\
\hline
\end{tabular}


Table 4. Component-total correlations

\begin{tabular}{ccc}
\hline Component & Total Score & P \\
\hline Habitual sleep efficiency & 0.90 & $<0.001$ \\
\hline Sleep latency & 0.70 & $<0.001$ \\
\hline Sleep duration & 0.78 & $<0.001$ \\
\hline Sleep disturbances & 0.66 & $<0.001$ \\
\hline Sleep quality & 0.69 & $<0.001$ \\
\hline Use of sleeping medication & 0.55 & $<0.001$ \\
\hline Daytime dysfunction & 0.66 & $<0.001$ \\
\hline
\end{tabular}

AJNPP

in Iranian people, in particular 1112 citizens in Arak City, Iran. Although the PSQI is frequently used in clinical and non-clinical research, its reliability and validity have not yet been determined in prior studies in this population.

Results of this study reveals the PSQI (Persian version) internal consistency as 0.65 that is consistent with the results of Mariman [13]. However, in Nazifi study, the internal consistency was determined as 0.55 in employees of Kerman hospitals [21]. KMO and Bartlett's test indicated that factor analysis was a good idea for our dataset. Factor analysis extracted two factors: perceived sleep quality and sleep efficiency. These two components of the PSQI were correlated and each had a separate and unique concept. The first component loaded on the perceived sleep quality and the second one on sleep efficiency. In Otte study, the first component was loaded on sleep efficiency [15].

The first and the second factors explained $29.88 \%$ and $21.87 \%$ of the variance, respectively. The results of this study were inconsistent with those of some other studies. Most other studies confirmed that the 3-factor PSQI model had acceptable performance and fit to the data $[10-13,21]$. However, the extracted factors were different in these studies. The results reported in Otte study show that a 2 -factor model was the best fit to data.

This conclusion could be attributed to cultural differences related to the quality of sleep differences among the various studies. However, the result of this study was similar to that of Otte in terms of the number of ex-

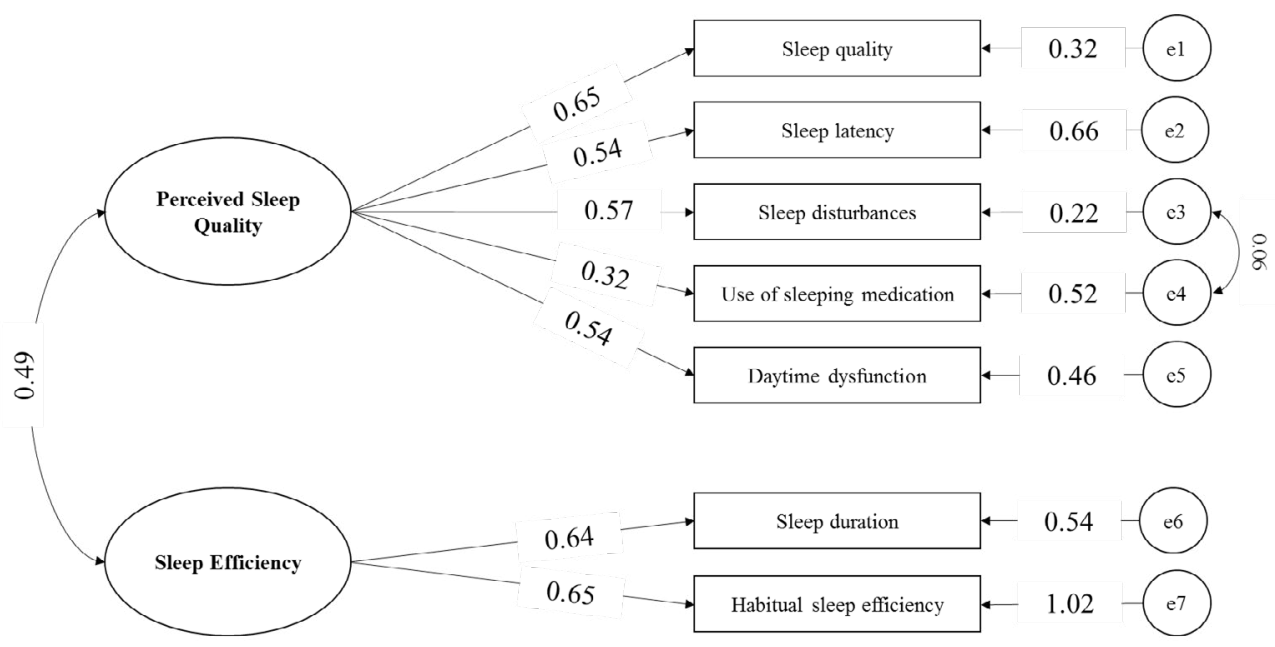

$\chi^{2}=27.906 ; \chi^{2} / \mathrm{d} . \mathrm{f}=2.326, \mathrm{p}<0.006 ; \mathrm{GFI}=0.993 ; \mathrm{AGFI}=0.984 ; \mathrm{RMR}=0.020 ; \mathrm{RMSEA}=0.034 ; \mathrm{CFI}=0.985 ; \mathrm{NNFI}=0.974$

Figure 1. Path diagram of the confirmatory analysis results concerning the PSQI questionnaire in the citizens of Arak city, Iran ( $n=1115)$ 
tracted factors and their components [15]. In summary, factor analysis confirmed that the Persian version of the PSQI with 2-factor model had legitimate validity and reliability in relation to Iranian people, at least the citizens in Arak City. These results also call for further validation in other populations.

\section{Conclusion}

The Persian version of the PSQI demonstrated satisfactory validity and reliability for our study sample. It was concluded that the PSQI is a useful instrument to measure the quality and patterns of sleep in citizens of Arak. Using a large sample and spotting more criteria in the validity and reliability of PSQI were the strong points of this study. However, some limitations of this study were first of all its research design which was cross-sectional. Only a 2 -factor solution was applied to estimations.

The coefficients in the path diagram were not adjusted for covariates such as age, sex, and education level. Arak population have three major ethnics, Fars, Lor, and Kord, thus the ethnic issue could be fit into the demographic section. In future studies, we suggest investigating the PSQI in other cities, with more information in the demographic section and adjusted coefficients for these covariates. We suggest to use PSQI in a case-control or a cohort study that cases are Iranian participants with any special psychosis. Also, by using similar statistical models to estimate coefficients (e.g. multiple linear regression, logistic regression), we can investigate the effect of covariates in the total score of PSQI.

\section{Ethical Considerations}

\section{Compliance with ethical guidelines}

This study was approved by the Ethics Committee of Arak University of Medical Sciences and each sample expressed his or her consent for participation in the study.

Funding

This work was supported by Arak University of Medical Sciences (Grant No.: 918).

\section{Authors contributions}

Conceptualization: Mohammad Gholi Mezerji, Parisa Naseri, Zahra Shayan; Methodology: All authors; Investigation: All authors; Writing-original draft: All authors; Writing-review \& editing: All authors; Funding acquisi- tion: All authors; Resources: All authors; and Supervision: Parisa Naseri, Zahra Shayan.

\section{Conflict of interest}

The authors declared no conflict of interest.

\section{Acknowledgements}

The authors would like to thank Dr. Nasrin Shokrpour in Center for Development of Clinical Research of Namazi Hospital for her editorial assistance.

\section{References}

[1] Altevogt BM, Colten HR. Sleep disorders and sleep deprivation: An unmet public health problem. Washington, DC.: National Academies Press; 2006.

[2] Buysse DJ, Reynolds III CF, Monk TH, Berman SR, Kupfer DJ. The Pittsburgh sleep quality index: A new instrument for psychiatric practice and research. Psychiatry Research. 1989; 28(2):193-213. [DOI:10.1016/0165-1781(89)90047-4]

[3] Grandner MA, Kripke DF, Yoon IY, Youngstedt SD. Criterion validity of the Pittsburgh sleep quality index: Investigation in a nonclinical sample. Sleep and Biological Rhythms. 2006; 4(2):129-36. [DOI:10.1111/j.1479-8425.2006.00207.x] [PMID] [PMCID]

[4] Monazzam MR, Hosseini M, Matin LF, Aghaei HA, Khosroabadi H, Hesami A. Sleep quality and general health status of employees exposed to extremely low frequency magnetic fields in a petrochemical complex. Journal of Environmental Health Science and Engineering. 2014; 12(1):78. [DOI:10.1186/2052-336X-12-78] [PMID] [PMCID]

[5] Adib Hajbaghery M, Izadi Avanji F, Akbari H. Quality of sleep and its related risk factors in hospitalized older patients in Kashan's hospitals, Iran 2009. Iranian Journal of Nursing and Midwifery Research 2012; 17(6):414-20. [PMID] [PMCID]

[6] Ait Aoudia M, Levy PP, Bui E, Insana S, De Fouchier C, Germain A et al. Validation of the French version of the Pittsburgh sleep quality index addendum for post traumatic stress disorder. European Journal of Psychotraumatology. 2013; 4(1):19298. [DOI:10.3402/ejpt. v4i0.19298] [PMID] [PMCID]

[7] Doi Y, Minowa M, Uchiyama M, Okawa M, Kim K, Shibui K, et al. Psychometric assessment of subjective sleep quality using the Japanese version of the Pittsburgh Sleep Quality Index (PSQI-J) in psychiatric disordered and control subjects. Psychiatry Research. 2000; 97(2-3):165-72. [DOI:10.1016/S0165-1781(00)00232-8]

[8] Knutson KL, Rathouz PJ, Yan LL, Liu K, Lauderdale DS. Stability of the Pittsburgh sleep quality index and the Epworth sleepiness questionnaires over 1 year in early middle-aged adults: The CARDIA study. Sleep. 2006; 29(11):1503-6. [DOI:10.1093/sleep/29.11.1503] [PMID]

[9] Kotronoulas GC, Papadopoulou CN, Papapetrou A, Patiraki E. Psychometric evaluation and feasibility of the Greek Pittsburgh Sleep Quality Index (GR-PSQI) in patients with cancer receiving chemotherapy. Supportive Care in Cancer. 2011; 19(11):1831-40. [DOI:10.1007/s00520-010-1025-4] [PMID] 
[10] Cole JC, Motivala SJ, Buysse DJ, Oxman MN, Levin MJ, Irwin MR. Validation of a 3-factor scoring model for the Pittsburgh sleep quality index in older adults. Sleep. 2006; 29(1):112-6. [DOI:10.1093/ sleep/29.1.112] [PMID]

[11] Aloba OO, Adewuya AO, Ola BA, Mapayi BM. Validity of the Pittsburgh Sleep Quality Index (PSQI) among Nigerian university students. Sleep Medicine. 2007; 8(3):266-70. [DOI:10.1016/j. sleep.2006.08.003] [PMID]

[12] Burkhalter H, Sereika SM, Engberg S, Wirz Justice A, Steiger J, De Geest S. Structure validity of the Pittsburgh sleep quality index in renal transplant recipients: A confirmatory factor analysis. Sleep and Biological Rhythms. 2010; 8(4):274-81. [DOI:10.1111/j.14798425.2010.00473.x]

[13] Mariman A, Vogelaers D, Hanoulle I, Delesie L, Tobback E, Pevernagie $D$. Validation of the three-factor model of the PSQI in a large sample of Chronic Fatigue Syndrome (CFS) patients. Journal of Psychosomatic Research. 2012; 72(2):111-3. [DOI:10.1016/j.jpsychores.2011.11.004] [PMID]

[14] Tomfohr LM, Schweizer CA, Dimsdale JE, Loredo JS. Psychometric characteristics of the Pittsburgh sleep quality index in English speaking non-hispanic whites and English and Spanish speaking Hispanics of Mexican descent. Journal of Clinical Sleep Medicine. 2013; 9(1):61-6. [DOI:10.5664/jcsm.2342]

[15] Otte JL, Rand KL, Carpenter JS, Russell KM, Champion VL. Factor analysis of the Pittsburgh sleep quality index in breast cancer survivors. Journal of Pain and Symptom Management. 2013; 45(3):6207. [DOI:10.1016/j.jpainsymman.2012.03.008] [PMID] [PMCID]

[16] Polit DF, Beck CT. The content validity index: Are you sure you know what's being reported? Critique and recommendations. Research in Nursing \& Health. 2006; 29(5):489-97. [DOI:10.1002/ nur.20147] [PMID]

[17] Costa ALS, Silva RMD, Mussi FC, Serrano PM, Graziano EDS, Batista KDM. Short version of the "instrument for assessment of stress in nursing students" in the Brazilian reality. Revista LatinoAmericana De Enfermagem. 2017; 25:e2976. [DOI:10.1590/15188345.2071.2976]

[18] Yong AG, Pearce $S$. A beginner's guide to factor analysis: Focusing on exploratory factor analysis. Tutorials in Quantitative Methods for Psychology. 2013; 9(2):79-94. [DOI:10.20982/tqmp.09.2.p079]

[19] Kline P. An easy guide to factor analysis. Abingdon: Routledge; 2014. [DOI:10.4324/9781315788135]

[20] Hair JF, Black WC, Babin BJ, Anderson RE, Tatham RL. [Análise multivariada de dados (Portuguese)]. Porto Alegre: Bookman editora; 2009.

[21] Nazifi M, Mokarami H, Akbaritabar A, Kalte HO, Rahi A. Psychometric properties of the Persian translation of Pittsburgh sleep quality index. Health Scope. 2014; 3(2):e15547. [DOI:10.17795/ jhealthscope-15547] 